\title{
Identification of potential biomarkers and drugs for papillary thyroid cancer based on gene expression profile analysis
}

\author{
TING QU ${ }^{1 *}$, YAN-PING LI ${ }^{2 *}$, XIAO-HONG LI ${ }^{1}$ and YAN CHEN ${ }^{1}$ \\ Departments of ${ }^{1}$ Pharmacy and ${ }^{2}$ Endodontics, The First Affiliated Hospital of Harbin Medical University, \\ Harbin, Heilongjiang 150001, P.R. China
}

Received September 17, 2015; Accepted September 29, 2016

DOI: $10.3892 / \mathrm{mmr} .2016 .5855$

\begin{abstract}
The present study aimed to systematically examine the molecular mechanisms of papillary thyroid cancer (PTC), and identify potential biomarkers and drugs for the treatment of PTC. Two microarray data sets (GSE3467 and GSE3678), containing 16 PTC samples and 16 paired normal samples, were downloaded from the Gene Expression Omnibus database. The differentially expressed genes (DEGs) were identified using the Linear Models for Microarray Analysis package. Subsequently, the common DEGs were screened for functional and pathway enrichment analysis using the Database for Annotation Visualization and Integrated Discovery. The representative interaction subnetwork was further derived using Molecular Complex Detection software. In addition, the potential drugs for the hub DEGs in the subnetwork were screened from DrugBank and the potential drug-like ligands, which interacted with genes, were selected using MTiOpenScreen. A total of 167 common DEGs, including 77 upregulated and 90 downregulated DEGs, were screened. The common DEGs were associated with the functions of plasma membrane, extracellular matrix, response to steroid hormone stimulus and cell adhesion, and the pathways of tyrosine metabolism and cell adhesion molecules were significantly enriched. A total of eight common DEGs (MET, SERPINA1, LGALS3, FN1, TNFRSF11B, LAMB3 and COL13A1) were involved in the subnetwork. The two drugs, lanoteplase and ocriplasmin, and four drugs, $\beta$-mercaptoethanol, recombinant $\alpha$ 1-antitrypsin, PPL-100 and API, were found for FN1 and SERPINA1, respectively. The common DEGs identified may be potential biomarkers for PCT. FN1 and SERPINA1 may be involved in PTC by regulating epithelial-to-mesenchymal tran-
\end{abstract}

Correspondence to: Dr Yan Chen, Department of Pharmacy, The First Affiliated Hospital of Harbin Medical University, 23 Youzheng Street, Nangang, Harbin, Heilongjiang 150001, P.R. China E-mail: yanchenphar@sina.com

*Contributed equally

Key words: papillary thyroid cancer, microarray analysis, biomarkers, drugs sition and responding to steroid hormone stimuli, respectively. Ocriplasmin, $\beta$-mercaptoethanol and recombinant $\alpha 1$-antitrypsin may be potential drugs for the treatment of PTC.

\section{Introduction}

Thyroid cancer is one of the most common types of endocrine malignancy, the incidence rate of which has rapidly increased during previous years $(1,2)$. It has been estimated that the annual number of cases of thyroid cancer diagnosed in the USA and the associated mortality rate are 12.9/100,000 and $0.5 / 100,000$ individuals, respectively (3). Papillary thyroid cancer (PTC), characterized by papillary architecture, psammoma bodies and specific nuclear features, including nuclear orientation, nuclear chromatin and nuclear grooving, is the major form of thyroid cancer, accounting for $80-85 \%$ of all thyroid malignancies (4). Although PTC has a favorable prognosis, certain cases exhibit aggressive clinical characteristics, including invasion and metastasis, and the management of PTC remains controversial $(5,6)$. Therefore, it is essential to investigate the molecular mechanisms of PTC and identify potential biomarkers, which may be beneficial for improving treatment.

The current understanding of the molecular mechanisms of PTC has improved significantly, particularly with the development of next generation sequencing and microarray technology. It has been reported that mutations of BRAF (T1796A and V599E) causing the activation of serine/threonine kinase may be an alternative mechanism of oncogenic mitogen-activated protein kinase pathway activation and are important in the development of PTC (7-9). The chemokine receptor, CXCR7 not only activates the phosphoinositide 3 -kinase/AKT and nuclear factor- $\kappa \mathrm{B}$ signaling pathways, but it also downregulates the Notch signaling pathway to regulate the growth and metastasis of PTC, according to gene expression profiling analysis of PTC (10). Amyloid precursor protein is overexpressed in PTC and may become a potential novel therapeutic target for PTC (11). It has been revealed that certain important upregulated microRNAs (miRs), including miR-221, miR-222 and miR-146, and the regulation of KIT are involved in the pathogenesis of PTC, based on previous microarray analysis of GSE3467 (12). Zhu et al (13) showed that Trefoil factor 3, cut-like homeobox 2 and forkhead box protein A2 are associated with the development of PTC, 
and the differentially expressed genes (DEGs) are primarily associated with positive regulation of gene expression, gene transcription and metabolic processes.

In the previous study by Zhu et al (13) only the GSE3678 DNA microarray data set was downloaded for DEG screening and subsequent enrichment analysis. In the present study, two DNA microarray data sets, GSE3467 and GSE3678, were combined for microarray analysis. The DEGs found to be simultaneously differentially expressed in the tumor samples of these two data sets were screened for enrichment analysis and interaction network construction. The potential drugs for the critical DEGs were also investigated. The present study may aid the diagnosis and treatment of PTC.

\section{Materials and methods}

Gene expression profiles. The two gene expression profiling data sets, GSE3467 and GSE3678, were downloaded from the Gene Expression Omnibus (GEO; http://www.ncbi.nlm.nih. gov/geo/) (14). GSE3467 (12) consisted of 18 paired tumor and normal thyroid tissue samples from nine patients with PTC. The GSE3678 data set contained seven PTC samples and seven paired normal thyroid tissue samples. The platform used for these two data sets was the GPL570 [HG-U133_Plus_2] Affymetrix Human Genome U133 Plus 2.0 array.

Data preprocessing and screening of DEGs. The probes without annotation of the gene expression profiles were filtered, and the probes were transformed into gene symbols. The average value of a gene symbol corresponding to multiple probes was calculated for the expression level analysis. The $\log 2$ transformation, background correction and data normalization were performed using the GeneChip Robust Multi-array Analysis (GCRMA) method within Bioconductor (http://www.bioconductor.org) (15). The DEGs were screened out by using the Linear Models for Microarray Analysis (Limma) package in $\mathrm{R}$ software (16) with the cut-off criteria of adjusted $\mathrm{P}<0.01$ and llog2 fold-change (FC) $\mid>2$.

Functional and pathway enrichment analyses. Functional and pathway enrichment analyses for the common DEGs were performed using the Database for Annotation, Visualization and Integrated Discovery online tools (17) based on the Gene Ontology (GO) (18) and Kyoto Encyclopedia of Genes and Genomes (19) databases. The GO terms in three categories, including biological process, cellular component and molecular function, were identified with $\mathrm{P}<0.05$. For pathway enrichment analysis, $\mathrm{P} \leq 0.05$ was set as the threshold.

Construction and analysis of the protein-protein interaction (PPI) network. The physical PPIs and pathway interactions were selected for PPI network construction using the Gene Multiple Association Network Integration Algorithm (http://www. genemania.org/) (20) plug-in of Cytoscape software (www. cytoscape.org; version 3.4.0). The representative subnetwork containing nodes with high levels of interconnection was further derived from the PPI network using Molecular Complex Detection software (baderlab.org/Software/MCODE) (21). In addition, the potential drugs of the hub DEGs in the subnetwork were searched using the DrugBank database (www. drugbank.ca) (22) and the potential drug-like ligands, which interacted with the genes, were screened from the diverse-lib database in MTiOpenScreen (bioserv.rpbs.univ-paris-diderot. fr/services/MTiOpenScreen) (23) according to Lipinski's rule of five (24).

\section{Results}

Identification of DEGs. Following data preprocessing, the standardized expression profiling data showed that the median values of gene expression were almost at the same level, indicating that the degree of standardization was sufficient to be used for the subsequent analysis (Fig. 1). A total of 384 and 262 DEGs were identified for GSE3467 and GSE3678, respectively. In addition, 167 genes were found to be simultaneously differentially expressed in the tumor samples of these two data sets (Fig. 2A). Among these 167 common DEGs, 77 genes were upregulated and 90 genes were downregulated. The correlation of the expression values for the 167 genes was 0.97 (P<2.2e-16; Fig. 2B).

Functional and pathway enrichment analysis. The common DEGs were primarily associated with the cellular components of the plasma membrane $(\mathrm{P}=2.60 \mathrm{E}-05)$ and integral to the membrane $(\mathrm{P}=0.002429)$. Certain common DEGs, including LC26A4, GABRB3, GABRB2 and CLCNKB, were significantly enriched in the anion transmembrane transporter activity $(\mathrm{P}=4.45 \mathrm{E}-04)$ and chloride anion binding $(\mathrm{P}=0.005756)$. In addition, SERPINA1, CITED1 and GHR were involved with response to steroid hormone stimulus $(\mathrm{P}=0.001849)$. FN1, LAMB3 and COL13A1 were enriched in cell adhesion $(\mathrm{P}=0.011121$; Table I).

In addition, two significant pathways were enriched for the common DEGs (Table II). The ALDH1A3, AOX1, HGD, $\mathrm{ADH} 1 \mathrm{~B}$ and TPO genes were significantly involved in the tyrosine metabolism pathway $(\mathrm{P}=0.001)$. Another five common DEGs, including NRCAM, NCAM1, CLDN1, CLDN10 and $\mathrm{CDH} 3$, were enriched in the cell adhesion molecules pathway $(\mathrm{P}=0.05)$.

Interaction network analysis. There were eight common DEGs, of which MET, SERPINA1, LGALS3, FN1, LAMB3, KRT19 and COL13A1 were upregulated, and TNFRSF11B was downregulated) in the constructed subnetwork (Fig. 3). The FN1 DEG can interact with SERPINA1, LGALS3, TNFRSF11B and LAMB3. There were also pathway interactions between any two of the FN1, COL13A1 and LAMB3 DEGs.

Potential drug identification. The potential drugs for FN1 and SERPINA1 were examined further, as these two DEGs showed higher degrees in the interaction subnetwork and may be critical in the regulatory process. The results revealed that two drugs, lanoteplase and ocriplasmin, were found for FN1, and four potential drugs, $\beta$-mercaptoethanol, recombinant $\alpha$ 1-antitrypsin, PPL-100 and API, were found for SERPINA1 (Table III). Lanoteplase is currently under clinical investigation and ocriplasmin, whose pharmacological action involves the cleavage of fibronectin protein, has been approved by the Food and Drug Administration (25). For SERPINA1, 
A
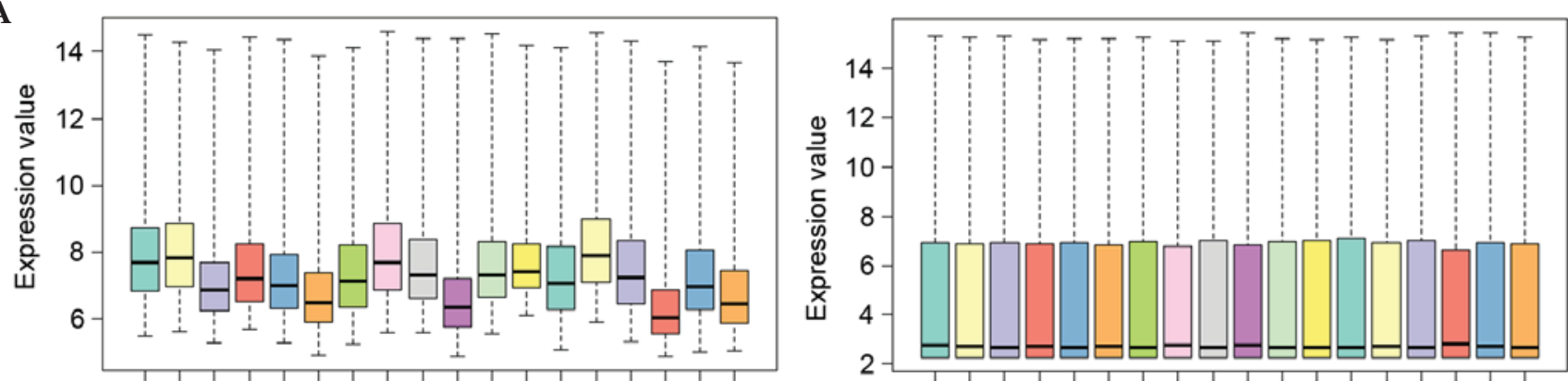

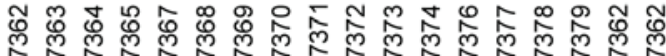

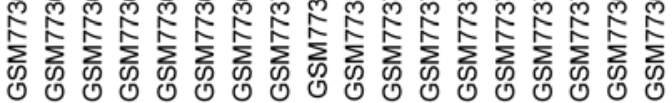

B
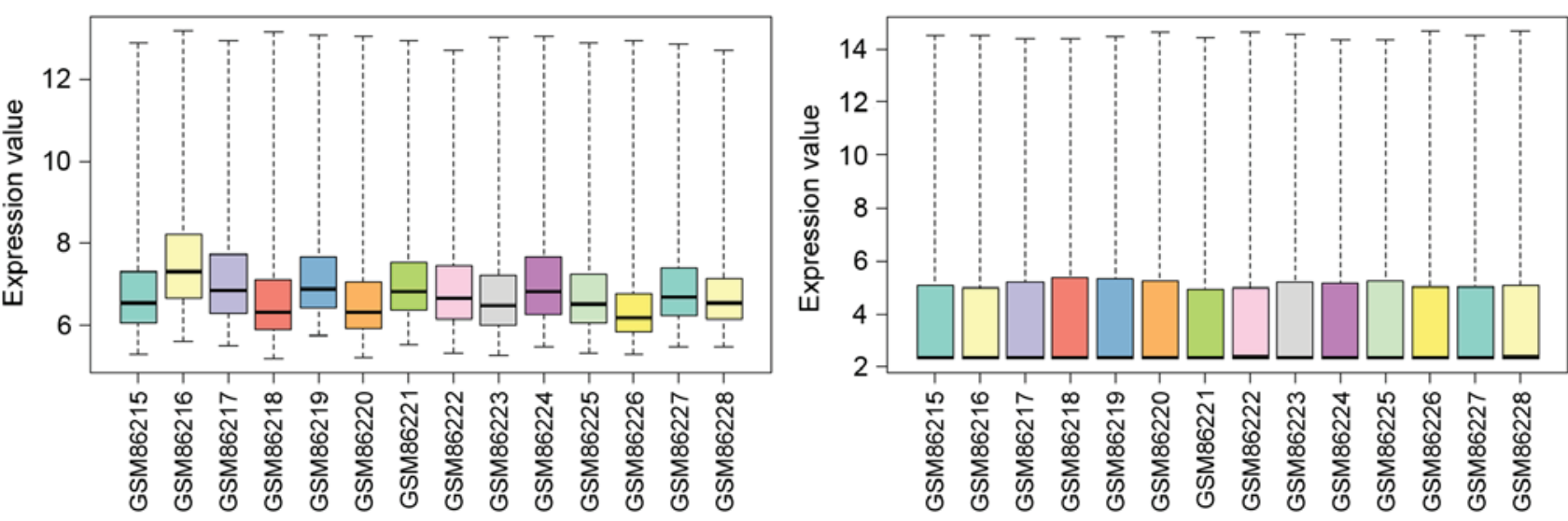

Figure 1. Box-plots of standardized expression data of paired tumor and normal thyroid tissue samples. (A) GSE3467; (B) GSE3678).

A

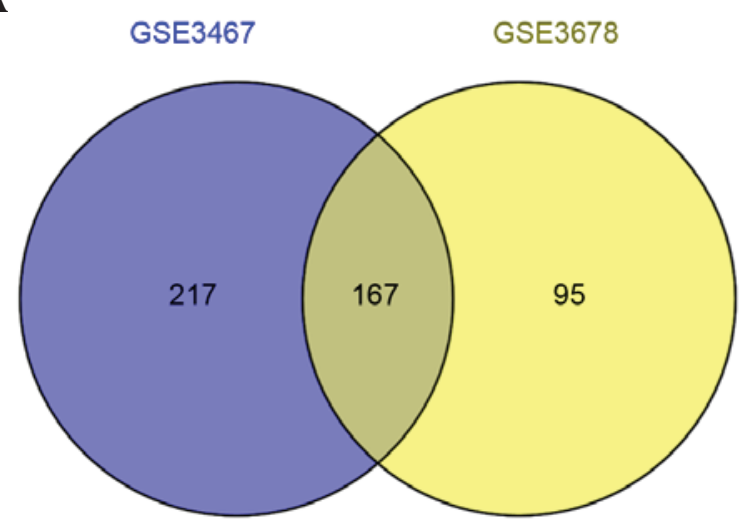

B

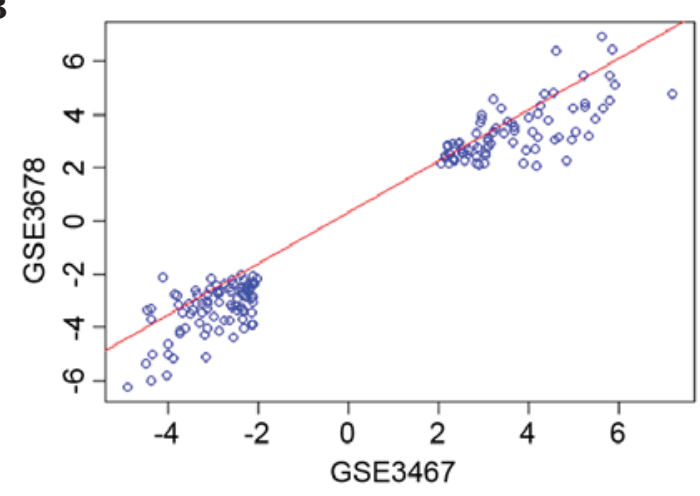

Figure 2. (A) Venn diagram of DEGs identified for the two data sets. (B) Correlation of the DEGs selected from GSE3467 with the DEGs selected from GSE3678. DEGs, differentially expressed genes.

$\beta$-mercaptoethanol is during experimental stage and the other three drugs are under clinical investigation.

In addition, five potential drug-like compounds with binding energies below -8.4 were screened out from the diverse-lib database in MTiOpenScreen (Table IV). The 24350490 compound, with a binding energy of $-8.7 \mathrm{kcal} / \mathrm{mol}$, has six hydrogen bond acceptors and one hydrogen bond donor. Another compound, 17506143, with a binding energy of $-8.6 \mathrm{kcal} / \mathrm{mol}$ has seven hydrogen bond acceptors and one hydrogen bond donor. The structural interactions between SERPINA1 and these two drug-like compounds are shown in
Fig. 4. The binding pocket of SERPINA1 contained His209 and SER47.

\section{Discussion}

In the present study, 167 genes were identified to be simultaneously differentially expressed in the tumor samples of GSE3467 and GSE3678. The subsequent pathway enrichment analysis revealed that ALDH1A3, AOX1, HGD, ADH1B and TPO were significantly involved in tyrosine metabolism. Several studies have revealed that the protooncogene, RET, 
Table I. Top ten enriched GO terms in the CC, MF and BP categories for the common differentially expressed genes.

\begin{tabular}{|c|c|c|c|c|c|}
\hline Category & ID & Term & Count & Genes & P-value \\
\hline $\mathrm{CC}$ & GO:0044459 & $\begin{array}{l}\text { Plasma membrane } \\
\text { part }\end{array}$ & 40 & $\begin{array}{l}\text { GPR125, STARD13, NRCAM, SDPR, } \\
\text { TPO, PLA2R1, ENTPD1, DPP4, FN1, } \\
\text { GHR, COL13A1, MET, SLC } 34 A 2 \ldots\end{array}$ & $2.60 \mathrm{E}-05$ \\
\hline $\mathrm{CC}$ & GO:000998 & Cell surface & 13 & $\begin{array}{l}\text { SCUBE3, GPR125, KIT, NCAM1, } \\
\text { NRCAM, CD36, GPM6A, LAYN, } \\
C D O N, T G F A, T P O, D P P 4, G H R\end{array}$ & $9.53 \mathrm{E}-05$ \\
\hline $\mathrm{CC}$ & GO:0005886 & Plasma membrane & 54 & $\begin{array}{l}\text { GABRB3, TPO, TGFA, SLC4A4, } \\
\text { GHR, PSD3, LIFR, SLC34A2, FN1, } \\
\text { MUC1, COL13A1, MET, SHANK2... }\end{array}$ & $3.56 \mathrm{E}-04$ \\
\hline $\mathrm{CC}$ & GO:0044420 & $\begin{array}{l}\text { Extracellular } \\
\text { matrix part }\end{array}$ & 7 & $\begin{array}{l}\text { SMOC2, LAMB3, SCUBE3, } \\
C O L 13 A 1, T F F 3, \text { ENTPD1, FN1 }\end{array}$ & 7.74E-04 \\
\hline $\mathrm{CC}$ & GO:0030054 & Cell junction & 14 & $\begin{array}{l}\text { GABRB3, GABRB2, COL13A1, } \\
P S D 3, C L D N 10, G A B B R 2, C D H 3, \\
A R H G A P 24, S H A N K 2, C A M K 2 N 1, \\
L A Y N, C L D N 1, D L G 2, D P P 4\end{array}$ & 0.001052 \\
\hline $\mathrm{CC}$ & GO:0044421 & $\begin{array}{l}\text { Extracellular } \\
\text { region part }\end{array}$ & 20 & $\begin{array}{l}\text { SCUBE3, LGALS3, COL13A1, CHI3L1, } \\
\text { KIT, SMOC2, LAMB3, TNFRSF11B, } \\
\text { TGFA, TFF3, ANGPTL1, SERPINA1, } \\
\text { CFI, GDF15, ENTPD1, PLA2R1, SFTPB, } \\
\text { FN1, GHR, BMP8A }\end{array}$ & 0.001350 \\
\hline $\mathrm{CC}$ & GO:0031012 & $\begin{array}{l}\text { Extracellular } \\
\text { matrix }\end{array}$ & 11 & $\begin{array}{l}\text { SMOC2, LAMB3, TNFRSF11B, LGALS3, } \\
\text { SCUBE3, COL13A1, CHI3L1, TFF3, } \\
\text { SERPINA1, ENTPD1, FN1 }\end{array}$ & 0.001416 \\
\hline $\mathrm{CC}$ & GO:0045211 & $\begin{array}{l}\text { Postsynaptic } \\
\text { membrane }\end{array}$ & 7 & $\begin{array}{l}\text { GABRB3, GABRB2, PSD3, GABBR2, } \\
\text { SHANK2, DLG2, CAMK2N1 }\end{array}$ & 0.001625 \\
\hline $\mathrm{CC}$ & GO:0044456 & $\begin{array}{l}\text { Synapse } \\
\text { part }\end{array}$ & 9 & $\begin{array}{l}\text { GABRB3, GABRB2, PSD3, GABBR2, } \\
L R R K 2, S H A N K 2, D L G 2, I T P R 1, C A M K 2 N 1\end{array}$ & 0.002101 \\
\hline $\mathrm{CC}$ & GO:0016021 & $\begin{array}{l}\text { Integral to } \\
\text { membrane }\end{array}$ & 66 & $\begin{array}{l}\text { GABBR2, TPO, DPP6, SLC4A4, DPP4, GHR, } \\
\text { SEL1L3, ENTPD1, MUC1, MET, TMEM163, } \\
\text { LAYN, BTBD11 .. }\end{array}$ & 0.002429 \\
\hline MF & GO:0043168 & $\begin{array}{l}\text { Anion } \\
\text { binding }\end{array}$ & 7 & $\begin{array}{l}S L C 26 A 4, G A B R B 3, G A B R B 2, C L C N K B \\
C T S C, G H R, S L C 34 A 2\end{array}$ & $2.15 \mathrm{E}-04$ \\
\hline MF & GO:0008509 & $\begin{array}{l}\text { Anion transmembrane } \\
\text { transporter activity }\end{array}$ & 8 & $\begin{array}{l}S L C 26 A 4, G A B R B 3, G A B R B 2, S L C 26 A 7, \\
A B C C 3, C L C N K B, S L C 4 A 4, S L C 34 A 2\end{array}$ & $4.45 \mathrm{E}-04$ \\
\hline $\mathrm{MF}$ & GO:0015103 & $\begin{array}{l}\text { Inorganic anion } \\
\text { transmembrane } \\
\text { transporter activity }\end{array}$ & 4 & SLC26A4, SLC26A7, SLC4A4, SLC34A2 & 0.003514 \\
\hline MF & GO:0031404 & Chloride ion binding & 5 & SLC26A4, GABRB3, GABRB2, CLCNKB, CTSC & 0.005756 \\
\hline MF & GO:0022838 & $\begin{array}{l}\text { Substrate specific } \\
\text { channel activity }\end{array}$ & 10 & $\begin{array}{l}\text { GABRB3, GPM6A, GABRB2, SLC26A7, AQP4, } \\
R Y R 2, C L C N K B, K C N J 2, K C N I P 4, I T P R 1\end{array}$ & 0.012085 \\
\hline MF & GO:0015267 & Channel activity & 10 & $\begin{array}{l}\text { GABRB3, GPM6A, GABRB2, SLC26A7, AQP4 } \\
R Y R 2, C L C N K B, K C N J 2, K C N I P 4, I T P R 1\end{array}$ & 0.014860 \\
\hline MF & GO:0022803 & $\begin{array}{l}\text { Passive transmembrane } \\
\text { transporter activity }\end{array}$ & 10 & $\begin{array}{l}\text { GABRB3, GPM6A, GABRB2, SLC26A7, AQP4, } \\
R Y R 2, C L C N K B, K C N J 2, K C N I P 4, I T P R 1\end{array}$ & 0.015074 \\
\hline $\mathrm{MF}$ & GO:0030246 & Carbohydrate binding & 9 & $\begin{array}{l}\text { NOD1, LGALS3, GALNT7, LAYN, COL13A1, } \\
\text { MRC2, CHI3L1, PLA2R1, FN1 }\end{array}$ & 0.017677 \\
\hline MF & GO:0016917 & GABA receptor activity & 3 & $G A B R B 3, G A B R B 2, G A B B R 2$ & 0.020798 \\
\hline MF & GO:0004714 & $\begin{array}{l}\text { Transmembrane receptor } \\
\text { protein tyrosine } \\
\text { kinase activity }\end{array}$ & 4 & MET, KIT, IRS1, EPHB1 & 0.024558 \\
\hline $\mathrm{BP}$ & GO:0007167 & $\begin{array}{l}\text { Enzyme linked receptor } \\
\text { protein signaling pathway }\end{array}$ & 11 & $\begin{array}{l}\text { TIAM1, MET, LIFR, ANGPTL1, PPM1 L, } \\
\text { KIT, GDF15, IRS1, EPHB1, CITED1, GHR }\end{array}$ & 0.001120 \\
\hline $\mathrm{BP}$ & GO:0009725 & $\begin{array}{l}\text { Response to } \\
\text { hormone stimulus }\end{array}$ & 10 & $\begin{array}{l}\text { KRT19, TNFRSF11B, AVPR IA, FABP4, } \\
\text { TFF3, SERPINA1, IRS1, CITED1, GHR, } \\
\text { SLC34A2 }\end{array}$ & 0.006298 \\
\hline
\end{tabular}


Table I. Continued.

\begin{tabular}{|c|c|c|c|c|c|}
\hline Category & ID & Term & Count & Genes & P-value \\
\hline $\mathrm{BP}$ & GO:0043627 & $\begin{array}{l}\text { Response to } \\
\text { estrogen stimulus }\end{array}$ & 6 & $\begin{array}{l}\text { KRT19, TNFRSF 11B, SERPINA1, } \\
\text { CITED1, GHR, SLC } 34 A 2\end{array}$ & 0.002681 \\
\hline $\mathrm{BP}$ & GO:0048545 & $\begin{array}{l}\text { Response to steroid } \\
\text { hormone stimulus }\end{array}$ & 8 & $\begin{array}{l}\text { KRT19, TNFRSF 11B, AVPR1A, FABP4, } \\
\text { SERPINA1, CITED1, GHR, SLC } 34 A 2\end{array}$ & 0.001849 \\
\hline $\mathrm{BP}$ & GO:0001570 & Vasculogenesis & 4 & HEY2, ZFPM2, CITED1, CITED2 & 0.006079 \\
\hline $\mathrm{BP}$ & GO:0001666 & Response to hypoxia & 6 & $\begin{array}{l}\text { PDE5A, RYR2, SERPINA1, ITPR1, DPP4, } \\
\text { CITED2 }\end{array}$ & 0.007532 \\
\hline BP & GO:0042060 & Wound healing & 7 & $\begin{array}{l}\text { CD36, SERPINA1, CDH3, ENTPD1, } \\
\text { PAPSS2, PROS1, FN1 }\end{array}$ & 0.007962 \\
\hline $\mathrm{BP}$ & GO:0060350 & $\begin{array}{l}\text { Endochondral bone } \\
\text { morphogenesis }\end{array}$ & 3 & COL13A1, RUNX2, GHR & 0.009053 \\
\hline BP & GO:0070482 & $\begin{array}{l}\text { Response to } \\
\text { oxygen levels }\end{array}$ & 6 & $\begin{array}{l}\text { PDE5A, RYR2, SERPINA1, ITPR 1, } \\
\text { DPP4, CITED2 }\end{array}$ & 0.009277 \\
\hline BP & GO:0007155 & Cell adhesion & 14 & $\begin{array}{l}\text { PLXNC1, MPZL2, COL13A1, CLDN10, } \\
C D H 3, C D H 6, N C A M 1, N R C A M, L A M B 3, \\
C D 36, C D O N, C L D N 1, E N T P D 1, F N 1\end{array}$ & 0.011121 \\
\hline
\end{tabular}

$\mathrm{GO}$, gene ontology; CC, cellular component; MF, molecular function; BP, biological process.

Table II. Enriched pathways for the common differentially expressed genes.

\begin{tabular}{llcll}
\hline Pathway_ID & \multicolumn{1}{c}{ Name } & Count & Genes \\
\hline hsa00350 & Tyrosine metabolism & 5 & ALDH1A3, AOX1, HGD, ADH1B, TPO \\
hsa04514 & Cell adhesion molecules & 5 & NRCAM, NCAM1, CLDN1, CLDN10, CDH3 \\
\hline
\end{tabular}

which encodes a tyrosine kinase cell surface receptor, is involved in the oncogenesis of PTC by activating its tyrosine kinase, either by rearrangement or mutation $(26,27)$. It has been confirmed that the mRNA expression level of TPO is markedly suppressed leading to low thyroid peroxidase activity in PTC (28). Thyroid peroxidase oxidizes iodide to form active iodine for addition onto tyrosine residues on thyroglobulin for the production of thyroid hormones (29). In the present study, TPO was also found to be significantly downregulated in the tumor samples. Therefore, ALDH1A3, AOX1, HGD, ADH1B and TPO may be important in PTC via their involvement in the tyrosine metabolism pathway. By contrast, the NRCAM, NCAM1, CLDN1, CLDN10 and CDH3 were significantly enriched in the pathway of cell adhesion molecules. Molecules associated with cell adhesion, for example ICAM-1, are known to be involved in papillary growth and proliferative capacity (30). The pathway enrichment analysis indicated that these common DEGs are involved in the pathogenesis and progression of PTC by regulating the pathways of tyrosine metabolism and cell adhesion molecules.

The representative subnetwork derived from the interaction network in the present study contained seven upregulated common DEGs (MET, SERPINA1, LGALS3, FN1, LAMB3 and COL13A1) and one downregulated DEG (TNFRSF11B). The MET, SERPINA1, LGALS3 and FN1 DEGs have been identified to be the potent biomarkers for PTC in previous studies $(31,32)$. The expression levels of FN1 and MET have been also reported to be upregulated in papillary thyroid carcinoma (33). The functional enrichment analysis revealed that FN1 was significantly enriched in the plasma membrane, extracellular matrix and cell adhesion. Vasko et al (34) showed that epithelial-to-mesenchymal transition is common in PTC invasion. It has been demonstrated that the genes differentially expressed in aggressive PTC are primarily associated with cell adhesion (35). In addition, FN1 can interact with SERPINA1, LGALS3, TNFRSF11B and LAMB3, according to the subnetwork. These results suggested that FN1 might be involved in PCT by regulating the epithelial-to-mesenchymal transition and interacting with other DEGs. Lanoteplase and ocriplasmin were identified to be the potential drugs for FN1. It has been reported that fibronectin is upregulated in PTC (36). Therefore, ocriplasmin may be of assistance in the prevention or treatment of PTC due to the cleavage of fibronectin.

Another common DEG with a higher degree, SERPINA1, was significantly associated with the functions of response to steroid hormone stimulus and response to estrogen stimulus in the present study. Vierlinger et al (37) showed that SERPINA1 can be considered as a single marker for PTC. In papillary thyroid tumors and normal thyroid tissue, estrogen and progesterone receptors have been identified in thyroid tissue responsive to steroid hormones (38). Kawabata et al (39) reported estrogen receptor $\alpha(\mathrm{ER} \alpha)$ is expressed at high 
Table III. Potential drugs for FN1 and SERPINA1

\begin{tabular}{llll}
\hline Target & \multicolumn{1}{c}{ Drug } & \multicolumn{1}{c}{ State } & Pharmacological action \\
\hline FN1 & Lanoteplase & Investigational & Unknown \\
& Ocriplasmin & Approved & Cleavage \\
SERPINA1 & $\beta$-mercaptoethanol & Experimental & Unknown \\
& Recombinant $\alpha$ 1-antitrypsin & Investigational & Unknown \\
& PPL-100 & Investigational & Unknown \\
& API & Investigational & Unknown \\
\hline
\end{tabular}

Table IV. Five drug-like compounds for SERPINA1.

\begin{tabular}{lcccccrr}
\hline Compound & $\begin{array}{c}\text { Energy } \\
(\mathrm{kcal} / \mathrm{mol})\end{array}$ & $\begin{array}{c}\text { nRot } \\
(\text { count })\end{array}$ & $\begin{array}{c}\text { Lead-like } \\
(\text { yes/no })\end{array}$ & $\begin{array}{c}\text { HBA } \\
(\text { count })\end{array}$ & $\begin{array}{c}\text { HBD } \\
(\text { count })\end{array}$ & $\begin{array}{c}\text { LogP } \\
(\mathrm{g} / \mathrm{mol})\end{array}$ & $\begin{array}{c}\text { TPSA } \\
\left(\AA^{2}\right)\end{array}$ \\
\hline 24350490 & -8.7 & 4 & $\mathrm{Y}$ & 6 & 1 & 3.49 & 405.86 \\
17506143 & -8.6 & 6 & $\mathrm{Y}$ & 7 & 1 & 3.50 & 409.44 \\
26649374 & -8.5 & 1 & $\mathrm{Y}$ & 7 & 2 & 2.43 & 366.41 \\
49671559 & -8.4 & 4 & $\mathrm{Y}$ & 7 & 0 & 3.14 & 445.92 \\
26639702 & -8.4 & 4 & $\mathrm{Y}$ & 6 & 0 & 3.51 & 389.47 \\
\hline
\end{tabular}

Energy, kacl/mol; nRo, number of rotatable bonds; Lead-like, drug lead-like or not; HBA, hydrogen bond acceptor; HBD, hydrogen bond donor; $\log$, the solubility of a potential oral drug; MW, molecular weight; TPSA, topological polar surface area.

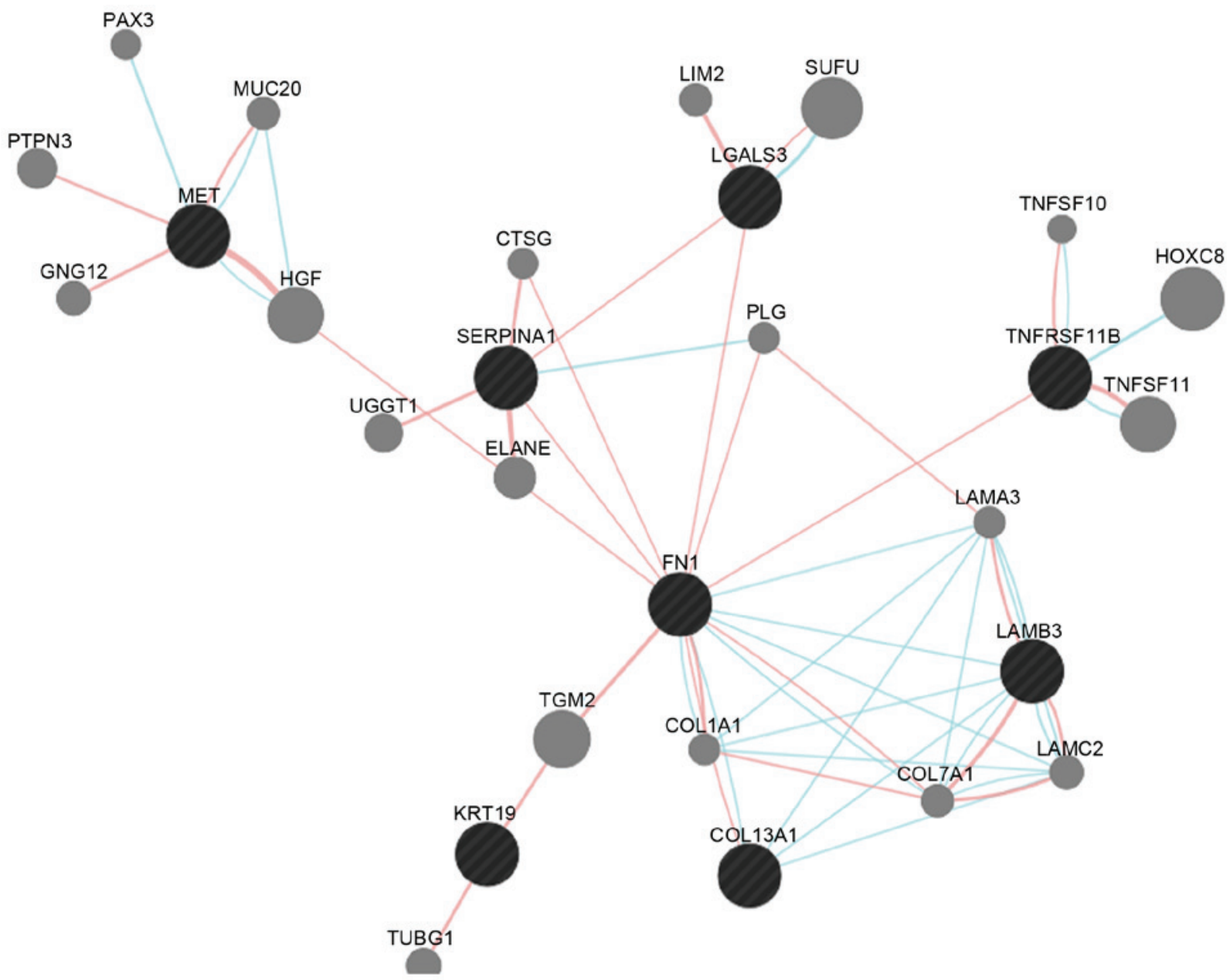

Figure 3. Constructed interaction sub-network. The black nodes indicate the differentially expressed genes. The red and blue lines represent the physical interactions and pathway interactions, respectively. The grey nodes represent genes that can be regulated by the DEGs or that link the DEGs together. 
A

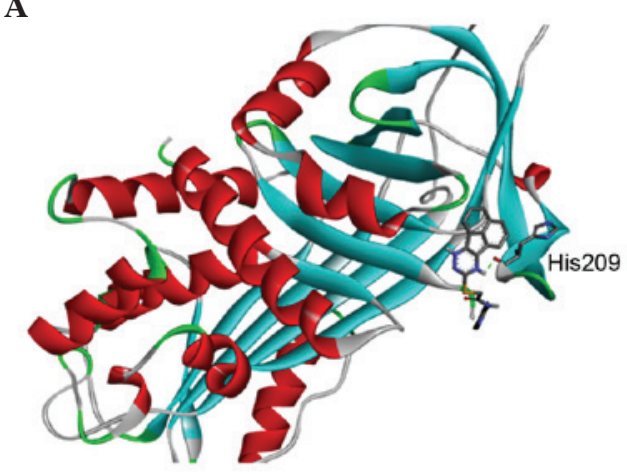

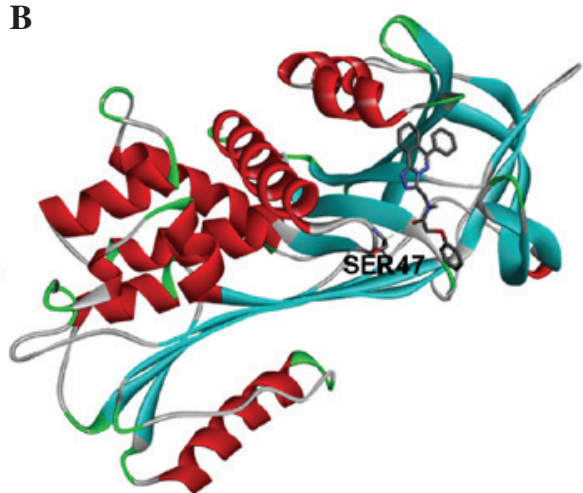

Figure 4. Structural interactions between SERPINA1 and the drug-like compounds, (A) 24350490 and (B) 17506143 . The green dashed lines represent hydrogen bonds.

levels in papillary thyroid cancer, suggesting that ER $\alpha$ may be involved in the development, physiology and pathology of papillary carcinoma. Therefore, upregulated expression levels of SERPINA1 may contribute to the response to steroid hormones in PTC. In the present study, four potential drugs were selected for SERPINA1. As His209 and SER47 are critical for the binding of compounds by forming hydrogen bonds (40), the amino acid around the pocket, which binds with compounds, may be critical for the function of SERPINA1. Therefore, $\beta$-mercaptoethanol and recombinant $\alpha 1$-antitrypsin may be the potential drugs for PTC. However, there were a number of limitations to the present study. The gene expression profiles of PTC at different stages require further analysis. In addition, the gene and protein expression levels of important DEGs may be better confirmed using experimental studies.

In conclusion, the common DEGs identified from GSE3467 and GSE3678 were found to have the potential for use as candidate biomarkers for PTC. The upregulated expression levels of FN1 and SERPINA1 may be involved in PTC by regulating the epithelial-to-mesenchymal transition and response to steroid hormones, respectively. Furthermore, ocriplasmin, $\beta$-mercaptoethanol and recombinant $\alpha 1$-antitrypsin may be potential drugs for the treatment of PTC. In further investigations, confirmation of the expression levels of important genes is required, as is the examination of PTC at different stages.

\section{References}

1. Nguyen QT, Lee EJ, Huang MG, Park YI, Khullar A and Plodkowski RA: Diagnosis and treatment of patients with thyroid cancer. Am Health Drug Benefits 8: 30-40, 2015.

2. Siegel R, Ma J, Zou Z and Jemal A: Cancer statistics, 2014. CA Cancer J Clin 64: 9-29, 2014

3. National Cancer Institute: SEER stat fact sheets: Thyroid cancer. http://seer.cancer.gov/statfacts/html/thyro.html. Accessed: May 20, 2015.

4. Schneider DF and Chen $\mathrm{H}$ : New developments in the diagnosis and treatment of thyroid cancer. CA Cancer J Clin 63: 374-394, 2013.

5. Yu XM, Wan Y, Sippel RS and Chen H: Should all papillary thyroid microcarcinomas be aggressively treated? An analysis of 18,445 cases. Ann Surg 254: 653-660, 2011.

6. Mazeh $\mathrm{H}$ and Chen $\mathrm{H}$ : Advances in surgical therapy for thyroid cancer. Nat Rev Endocrinol 7: 581-588, 2011.

7. Cohen Y, Xing M, Mambo E, Guo Z, Wu G, Trink B, Beller U, Westra WH, Ladenson PW and Sidransky D: BRAF mutation in papillary thyroid carcinoma. J Natl Cancer Inst 95: 625-627, 2003
8. Soares P, Trovisco V, Rocha AS, Lima J, Castro P, Preto A, Máximo V, Botelho T, Seruca R and Sobrinho-Simões M: BRAF mutations and RET/PTC rearrangements are alternative events in the etiopathogenesis of PTC. Oncogene 22: 4578-4580, 2003.

9. Fukushima T, Suzuki S, Mashiko M, Ohtake T, Endo Y, Takebayashi Y, Sekikawa K, Hagiwara K and Takenoshita S: BRAF mutations in papillary carcinomas of the thyroid. Oncogene 22: 6455-6457, 2003.

10. Zhang H, Teng X, Liu Z, Zhang L and Liu Z: Gene expression profile analyze the molecular mechanism of CXCR7 regulating papillary thyroid carcinoma growth and metastasis. J Exp Clin Cancer Res 34: 16, 2015.

11. Yang Z, Fan Y, Deng Z, Wu B and Zheng Q: Amyloid precursor protein as a potential marker of malignancy and prognosis in papillary thyroid carcinoma. Oncol Lett 3: 1227-1230, 2012.

12. He H, Jazdzewski K, Li W, Liyanarachchi S, Nagy R, Volinia S, Calin GA, Liu CG, Franssila K, Suster S, et al: The role of microRNA genes in papillary thyroid carcinoma. Proc Natl Acad Sci USA 102: 19075-19080, 2005.

13. Zhu X, Yao J and Tian W: Microarray technology to investigate genes associated with papillary thyroid carcinoma. Mol Med Rep 11: 3729-3733, 2015.

14. Barrett T, Troup DB, Wilhite SE, Ledoux P, Rudnev D, Evangelista C, Kim IF, Soboleva A, Tomashevsky M and Edgar R: NCBI GEO: Mining tens of millions of expression profiles-database and tools update. Nucleic Acids Res 35 (Database issue): D760-D765, 2007.

15. Gentleman RC, Carey VJ, Bates DM, Bolstad B, Dettling M, Dudoit S, Ellis B, Gautier L, Ge Y, Gentry J, et al: Bioconductor: Open software development for computational biology and bioinformatics. Genome Biol 5: R80, 2004.

16. Smyth GK: Limma: linear models for microarray data. In: Bioinformatics and computational biology solutions using R and Bioconductor. Gentleman R, Varey VJ, Huber W, Irizarry RA and Dudoit S (eds). 1st edition. Springer-Verlag, New York, NY, pp397-420, 2005.

17. Huang da W, Sherman BT and Lempicki RA: Systematic and integrative analysis of large gene lists using DAVID bioinformatics resources. Nat Protoc 4: 44-57, 2009.

18. Harris MA, Clark J, Ireland A, Lomax J, Ashburner M, Foulger R, Eilbeck K, Lewis S, Marshall B, Mungall C, et al: The Gene Ontology (GO) database and informatics resource. Nucleic Acids Res 32 (Database issue): D258-D261, 2004.

19. Kanehisa M and Goto S: KEGG: Kyoto encyclopedia of genes and genomes. Nucleic Acids Res 28: 27-30, 2000.

20. Warde-Farley D, Donaldson SL, Comes O, Zuberi K, Badrawi R, Chao P, Franz M, Grouios C, Kazi F, Lopes CT, et al: The GeneMANIA prediction server: Biological network integration for gene prioritization and predicting gene function. Nucleic acids Res 38 (Web Server issue): W214-W220, 2010.

21. Bader GD and Hogue CW: An automated method for finding molecular complexes in large protein interaction networks. BMC Bioinformatics 4: 2, 2003.

22. Wishart DS, Knox C, Guo AC, Shrivastava S, Hassanali M, Stothard P, Chang Z and Woolsey J: DrugBank: A comprehensive resource for in silico drug discovery and exploration. Nucleic Acids Res 34 (Database issue): D668-D672, 2006. 
23. Labbé CM, Rey J, Lagorce D, Vavruša M, Becot J, Sperandio O, Villoutreix BO, Tufféry P and Miteva MA: MTiOpenScreen: A web server for structure-based virtual screening. Nucleic Acids Res 43: W448-W454, 2015.

24. Lipinski CA, Lombardo F, Dominy BW and Feeney PJ: Experimental and computational approaches to estimate solubility and permeability in drug discovery and development settings. Adv Drug Deliv Rev 46: 3-26, 2001.

25. Collen D and Lijnen HR: Tissue-type plasminogen activator: A historical perspective and personal account. J Thromb Haemostasis 2: 541-546, 2004.

26. Komminoth P: The RET proto-oncogene in medullary and papillary thyroid carcinoma. Molecular features, pathophysiology and clinical implications. Virchows Arch 431: 1-9, 1997.

27. Eberhardt NL, Grebe SK, McIver B and Reddi HV: The role of the PAX8/PPARgamma fusion oncogene in the pathogenesis of follicular thyroid cancer. Mol Cell Endocrinol 321: 50-56, 2010.

28. Tanaka T, Umeki K, Yamamoto I, Sugiyama S, Noguchi S and Ohtaki S: Immunohistochemical loss of thyroid peroxidase in papillary thyroid carcinoma: Strong suppression of peroxidase gene expression. J Pathol 179: 89-94, 1996.

29. Ruf J and Carayon P: Structural and functional aspects of thyroid peroxidase. Arch Biochem Biophys 445: 269-277, 2006.

30. Buitrago D, Keutgen X, Crowley M, Filicori F, Aldailami H, Hoda R, Liu YF, Hoda RS, Scognamiglio T, Jin M, et al: Intercellular adhesion molecule-1 (ICAM-1) is upregulated in aggressive papillary thyroid carcinoma. Ann Surg Oncol 19: 973-980, 2012.

31. Jarząb B, Wiench M, Fujarewicz K, Simek K, Jarzab M, Oczko-Wojciechowska M, Wloch J, Czarniecka A, Chmielik E, Lange D, et al: Gene expression profile of papillary thyroid cancer: Sources of variability and diagnostic implications. Cancer Res 65: 1587-1597, 2005.

32. Griffith OL, Melck A, Jones SJ and Wiseman SM: Meta-analysis and meta-review of thyroid cancer gene expression profiling studies identifies important diagnostic biomarkers. J Clin Oncol 24: 5043-5051, 2006.
33. da Silveira Mitteldorf CA, de Sousa-Canavez JM, Leite KR, Massumoto C and Camara-Lopes LH: FN1, GALE, MET, and QPCT overexpression in papillary thyroid carcinoma: Molecular analysis using frozen tissue and routine fine-needle aspiration biopsy samples. Diagn Cytopathol 39: 556-561, 2011.

34. Vasko V,Espinosa AV, Scouten W, He H, Auer H, Liyanarachchi S, Larin A, Savchenko V, Francis GL, de la Chapelle A, et al: Gene expression and functional evidence of epithelial-to-mesenchymal transition in papillary thyroid carcinoma invasion. Proc Natl Acad Sci USA 104: 2803-2808, 2007.

35. Yang Z, Yuan Z, Fan Y, Deng X and Zheng Q: Integrated analyses of microRNA and mRNA expression profiles in aggressive papillary thyroid carcinoma. Mol Med Rep 8: 1353-1358, 2013

36. Wasenius VM, Hemmer S, Kettunen E, Knuutila S, Franssila K and Joensuu $\mathrm{H}$ : Hepatocyte growth factor receptor, matrix metalloproteinase-11, tissue inhibitor of metalloproteinase-1, and fibronectin are up-regulated in papillary thyroid carcinoma: A cDNA and tissue microarray study. Clin Cancer Res 9: 68-75, 2003.

37. Vierlinger K, Mansfeld MH, Koperek O, Nöhammer C, Kaserer K and Leisch F: Identification of SERPINA1 as single marker for papillary thyroid carcinoma through microarray meta analysis and quantification of its discriminatory power in independent validation. BMC Med Genomics 4: 30, 2011.

38. Lewy-Trenda I: Estrogen and progesterone receptors in neoplastic and non-neoplastic thyroid lesions. Pol J Pathol 53: 67-72, 2002.

39. Kawabata W, Suzuki T, Moriya T, Fujimori K, Naganuma H, Inoue S, Kinouchi Y, Kameyama K, Takami H, Shimosegawa T and Sasano H: Estrogen receptors (alpha and beta) and 17beta-hydroxysteroid dehydrogenase type 1 and 2 in thyroid disorders: Possible in situ estrogen synthesis and actions. Mod Pathol 16: 437-444, 2003.

40. Derewenda ZS and Derewenda U: The structure and function of platelet-activating factor acetylhydrolases. Cell Mol Life Sci 54: 446-455, 1998. 